\title{
Inhibition of caspase mediated apoptosis restores muscle function after crush injury in rat skeletal muscle
}

\author{
Ioannis Stratos $\cdot$ Zhengdong $\mathrm{Li} \cdot$ Robert Rotter $\cdot$ \\ Philipp Herlyn • Thomas Mittlmeier • \\ Brigitte Vollmar
}

Published online: 17 November 2011

(c) The Author(s) 2011. This article is published with open access at Springerlink.com

\begin{abstract}
Although muscle regeneration after injury is accompanied by apoptotic cell death, prolonged apoptosis inhibits muscle restoration. The goal of our study was to provide evidence that inhibition of apoptosis improves muscle function following blunt skeletal muscle injury. Therefore, 24 rats were used for induction of injury to the left soleus muscle using an instrumented clamp. All animals received either $3.3 \mathrm{mg} / \mathrm{kg}$ i.p. of the pan-caspase inhibitor Z-valinyl-alanyl-DL-aspartyl-fluoromethylketone (z-VAD.fmk) ( $n=12$ animals) or equivalent volumes of the vehicle solution DMSO ( $n=12$ animals) at 0 and $48 \mathrm{~h}$ after trauma. After assessment of the fast twitch and tetanic contraction capacity of the muscle at days 4 and 14 post injury, sampling of muscle tissue served for analysis of cell apoptosis (cleaved caspase 3 immunohistochemistry), cell proliferation (BrdU immunohistochemistry) as well as of muscle tissue area and myofiber diameter (HE planimetric analysis). Muscle strength analysis after 14 days in the z-VAD.fmk treated group revealed a significant increase in relative muscle strength when compared to the DMSO treated group. In contrast to the DMSO treated injured muscle, showing a transient switch towards a fast-twitching muscle phenotype (significant increase of the twitch-totetanic force ratio), z-VAD.fmk treated animals showed an enhanced healing process with a faster restoration of the twitch-to-tetanic force ratio towards the physiological slow-twitching muscle phenotype. This enhancement of
\end{abstract}

I. Stratos · Z. Li · P. Herlyn · B. Vollmar ( $\square)$ Institute of Experimental Surgery, University of Rostock, Schillingallee 69a, 18057 Rostock, Germany e-mail: brigitte.vollmar@med.uni-rostock.de

I. Stratos - R. Rotter - P. Herlyn · T. Mittlmeier Department of Trauma and Reconstructive Surgery, University of Rostock, Rostock, Germany muscle function was accompanied by a significant decrease of cell apoptosis and cell proliferation at day 4 as well as by a significant increase of muscle tissue area at day 4 . At day 14 after injury z-VAD.fmk treated animals presented with a significant increase of myofiber diameter compared to the DMSO treated animals. Thus, z-VAD.fmk could provide a promising option in the anti-apoptotic therapy of muscle injury.

Keywords Muscle regeneration · Crush injury · z-VAD.fmk · Apoptosis

\section{Introduction}

Musculoskeletal diseases and soft tissue traumata are a major burden on society, representing the most common cause of pain and impaired function in sports worldwide [1, 2]. From a clinical point of view, muscle injury represents a serious factor limiting the therapeutic outcome in the fields of trauma surgery, transplantation, plastic surgery and orthopedics.

A crucial requirement for the development of novel therapeutic strategies after muscle injuries is to understand how muscle regeneration is regulated and muscle loss occurs. According to current therapeutic strategies and daily clinical practice, muscle injuries predominantly heal with residual deficits since till now no causal treatment options exist [3]. As a result, complications such as enduring pain, atrophy and impaired functionality are often encountered. Several groups have attempted to improve muscle recovery using a variety of drugs, applying cytokines, transplanting cells or even modifying genes in the muscle $[4,5]$. Unfortunately poor study results or limited applicability of the methods are indicating that the research 
field of muscle injury and regeneration is open for further investigations.

A vital process of muscle regeneration is muscle cell apoptosis. This mode of cell death occurs normally during aging [6] and growth [7] of the muscle but also under pathologic conditions like upon muscle injury [8,9] or in neuromuscular diseases [10]. Furthermore, programmed cell death is an important regulatory process for tissue homeostasis and normal development [11, 12]. Although muscle regeneration after injury is accompanied by apoptotic cell death, prolonged apoptosis inhibits muscle restoration after trauma [9]. From a cell-biological point of view, the apoptotic process can be induced by a variety of pathways, which are mediated by ligands, pro-apoptotic proteins, reactive oxygen species, cytochrome c or mitochondrial proteins like apoptosis inducing factor or endonuclease $G$ [13, 14]. Key proteins during apoptosis are the members of the caspase family, which regulate apoptosis or irreversibly induce programmed cell death [14].

The goal of our study was to provide compelling evidence that caspase inhibition via the pan-caspase inhibitor Z-valinyl-alanyl-DL-aspartyl-fluoromethylketone (z-VAD. fmk) improves muscle function following blunt skeletal muscle injury. We hypothesized that animals with a muscle injury and apoptosis inhibition would benefit by amplified muscle function and improved muscle regeneration.

\section{Materials and methods}

\section{Animal model}

For this purpose 24 juvenile male Wistar rats (300-325 g body weight (bw), 62-67 days old; Charles River Laboratories, Sulzfeld, Germany) were used for the experiments and were kept on water and standard laboratory chow ad libitum. Under pentobarbital sodium anesthesia $(55 \mathrm{mg} /$ kg bw i.p.; Narcoren, Merial, Hallbergmoos, Germany) the left lower limb was shaved and disinfected with povidoneiodine. Through a $2 \mathrm{~cm}$ posterolateral longitudinal incision of the skin and the underlying fascia from the lateral gastrocnemius head to the Achilles tendon the soleus muscle was mobilized. The blunt injury was induced on the left soleus muscle via an instrumented clamp (area of contact between muscle tissue and clamp: $10 \mathrm{~mm}^{2}$ ), which allowed a standardized force application of $25 \mathrm{~N}$ for $10 \mathrm{~s}$ (DMC PLUS, HBM Hottinger Baldwin Messtechnik GmbH Germany). The muscle was manually clamped seven times over its complete length (total crushed area: $70 \mathrm{~mm}^{2}$ ) with exception of the entry point of the supplying neurovascular structures, which arise from the mid part of the medial gastrocnemius [9, 15, 16]. For immunohistochemical analysis of muscle cell proliferation animals received a single intraperitoneal injection of BrdU $(50 \mathrm{mg} / \mathrm{kg}-48 \mathrm{~h}$ prior to the final experiments at either day 4 or 14 postinjury), similarly as already described [9, 17, 18].

\section{Muscle strength measurement}

For in vivo assessment of muscle strength animals were reanesthetized at day 4 and 14 post-injury. After bilateral exposure of the sciatic nerve and the soleus muscle the Achilles tendon was cut and the lower extremity was fixed into the muscle force-measuring device (Experimetria, Budapest, Hungary). The sciatic nerve was subsequently stimulated with $9 \mathrm{~mA} / 75 \mathrm{~Hz}$ bipolar five times, $0.1 \mathrm{~s}$ (8 periods) with $5 \mathrm{~s}$ interval between the pulses. After this fast twitch stimulation protocol maximal strength was measured by application of $9 \mathrm{~mA} / 75 \mathrm{~Hz}$ pulses for the five times, $3 \mathrm{~s}$ each with $5 \mathrm{~s}$ intervals, reaching tetany in all cases. Contraction forces under fast twitch and tetanic stimulation were analyzed by calculating the mean of the maximal values from first five consecutive contractions and given as percentage of the corresponding values of the contralateral non-injured muscle. After completion of muscle strength measurements experiments were terminated by excision of the injured left soleus muscle for subsequent histology and immunohistochemistry.

Histology and immunohistochemistry

For immunohistochemical demonstration of BrdU in the muscle tissue we used a monoclonal mouse anti-BrdU antibody (1:50; No. M0744, Dako Cytomation, Hamburg, Germany). 3,3'-diaminobenzidine was used as chromogen. Sections were analyzed by light microscopy (BX 51, Olympus, Hamburg, Germany), using a $\times 40$ objective (numerical aperture 0.65). BrdU-positive cells were counted within the muscle tissue from the proximal to the distal insertion ( $\sim 30$ consecutive observation fields) and data were given as cells per $\mathrm{mm}^{2}$.

To determine apoptotic cell death cleaved caspase 3 staining was performed using a rabbit anti-cleaved caspase 3 (1:500, No. 9661, Cell Signaling Technology, Frankfurt, Germany) antibody. 3,3'-diaminobenzidine was used as chromogen. Sections were analyzed by light microscopy (BX 51, Olympus), using a $\times 40$ objective (numerical aperture 0.65). Cleaved caspase 3 positive cells were counted within the muscle tissue from the proximal to the distal insertion ( $\sim 30$ consecutive observation fields) and data were given as cells per $\mathrm{mm}^{2}$.

To elucidate the coverage of muscle tissue we calculated the muscle tissue area in percent to the entire observation field in entire hematoxylin-eosin (HE) stained tissue. For the HE analysis tissue was stained in Mayer's hemalum solution, rinsed in $0.1 \% \mathrm{HCl}$, stained in Eosin solution, and 
finally washed in water and ascending alcohol series. Highdensity digital images of the entire muscle were acquired by means of a digital camera (Colorview II, Olympus) and planimetrically analyzed using Photoshop (Photoshop7, Adobe Systems Europe, Uxbridge, UK). In the same sections we analyzed the muscle fiber diameter in $0.01 \mathrm{~mm}^{2}$ of the penumbra area (4 observation fields) using a $\times 20$ objective and the light microscopic imaging software $\mathrm{Cell}^{\mathrm{D}}$ (Olympus).

By manually clamping the left soleus muscle seven times over its complete length we produced an inhomogeneous tissue injury with areas of complete distraction and of moderate to almost no injury ("penumbra") [18]. We started to count the positive cells from the proximal to the distal insertion of the muscle disregarding the heterogenous morphology of the muscle as previously described by our group [18]. The complete loss of visible muscle cells in the severely injured parts of muscle tissue did not allow to express the positive cells per number of all muscle cells in the observation field. Quantitative analysis of immunohistochemical and histological staining is thus given as positive cells per $\mathrm{mm}^{2}$.

\section{Molecular biology}

By means of Western blot we analyzed the protein expression of B-cell lymphoma-2 protein (bcl-2) and bcl-2associated-X protein (bax). For this purpose, muscle tissue was homogenized in lysis buffer (1 M Tris, $\mathrm{pH} 7.5,5 \mathrm{M}$ $\mathrm{NaCl}, 250 \mathrm{mM}$ EDTA, $10 \%$ Triton- $\times 100,4 \% \mathrm{NaN}_{3}$, and $100 \mathrm{mM}$ PMSF), incubated for $30 \mathrm{~min}$ on ice, and centrifuged for $15 \mathrm{~min}$ at $10,000 \times g$. Before use, all buffers received a protease inhibitor cocktail (1:100 vol/vol; Sigma-Aldrich, Hamburg, Germany). Protein concentrations were determined using the BCA protein assay (Pierce, Rockford, IL) with bovine serum albumin as standard. Protein extracts $(40 \mu \mathrm{g})$ were separated discontinuously on sodium dodecyl sulfate polyacrylamide gels (12\% SDSPAGE) and transferred to a polyvinylidenedifluoride membrane (Immobilon-P transfer membrane; Millipore, Billerica, MA). After blockade of nonspecific binding sites membranes were incubated for $2 \mathrm{~h}$ at room temperature with primary antibodies followed by secondary antibodies (primary bax antibody: 1:250, BD-556467, Becton-Dickinson, Franklin Lakes, NJ and secondary bax antibody: 1:20.000, A9044, Sigma-Aldrich; primary bcl-2 antibody: 1:500, BD-610538, Becton-Dickinson and secondary bcl-2 antibody: 1:20.000, A9044, Sigma-Aldrich; primary B-actin antibody: 1:20.000, A5441, Sigma-Aldrich and secondary ß-actin antibody: 1:60.000, A9044, SigmaAldrich). Protein expression was visualized by means of luminol-enhanced chemiluminescence (ECL Plus; Amersham Pharmacia Biotech, Freiburg, Germany), digitalized with ChemiDocTM XRS System (Bio-Rad Laboratories, Munich, Germany) and calculated in relation to the B-actin expression.

\section{Experimental groups}

Two experimental groups of animals were included in the present study: z-VAD group, i.e. animals which underwent crush injury of the left soleus muscle and received injection of the pan-caspase inhibitor z-VAD.fmk $(3.3 \mathrm{mg} / \mathrm{kg}$ b.w. i.p.; z-VAD.fmk, Sigma-Aldrich Chemie GmbH, Germany) at 0 and $48 \mathrm{~h}$ after injury; control group, i.e. animals which underwent crush injury of the left soleus muscle and received equivalent volumes of DMSO $(1.0 \mathrm{ml} / \mathrm{kg}$ b.w. DMSO i.p.) at 0 and $48 \mathrm{~h}$ after injury. Subsequent analysis was performed 4 and 14 days after injury induction $(n=6$ animals per time point and group).

\section{Statistical analysis}

All data are expressed as means \pm standard error of the mean (SEM). Differences between groups and time points were assessed using an unpaired Student's $t$-test. Statistical significance was set at $P<0.05$. Statistics were performed using the GraphPad Prism 5.0 software (GraphPad Software, San Rafael, CA).

\section{Results}

All animals that underwent open crush injury awoke from anesthesia without complications. Usage of the left hind limb was found only slightly reduced during the first one to three days. There were no other signs of discomfort or illness. The operated extremity did not show macroscopic signs of local infection or impaired wound healing in any animal.

The use of this injury model induced both local damage and serious functional impairment in the injured muscle, which lasted up to 14 days after injury. As a result 4 days upon muscle injury twitch force was found reduced in both groups reaching mean values between 13 and $16 \%$ compared to the force of the contralateral muscle (Fig. 1a; $P=0.28)$. At the same time point corresponding mean values of the tetanic force ranged between 16 and $25 \%$ (Fig. 1b; $P=0.44$ ). Interestingly, caspase inhibition mediated by injection of $\mathrm{z}$-VAD.fmk enhanced the muscle force at day 14 , as given by a 1.6 fold increase of the twitch force $(P=0.001)$ and a 1.3 fold escalation of the tetanic force $(P=0.27)$ when compared to control (Fig. 1a and b).

Traumatized muscle tissue presented with a significant rise of the twitch-to-tetanic force ratio in both groups at day 4 after injury induction, indicating a transient switch to a 

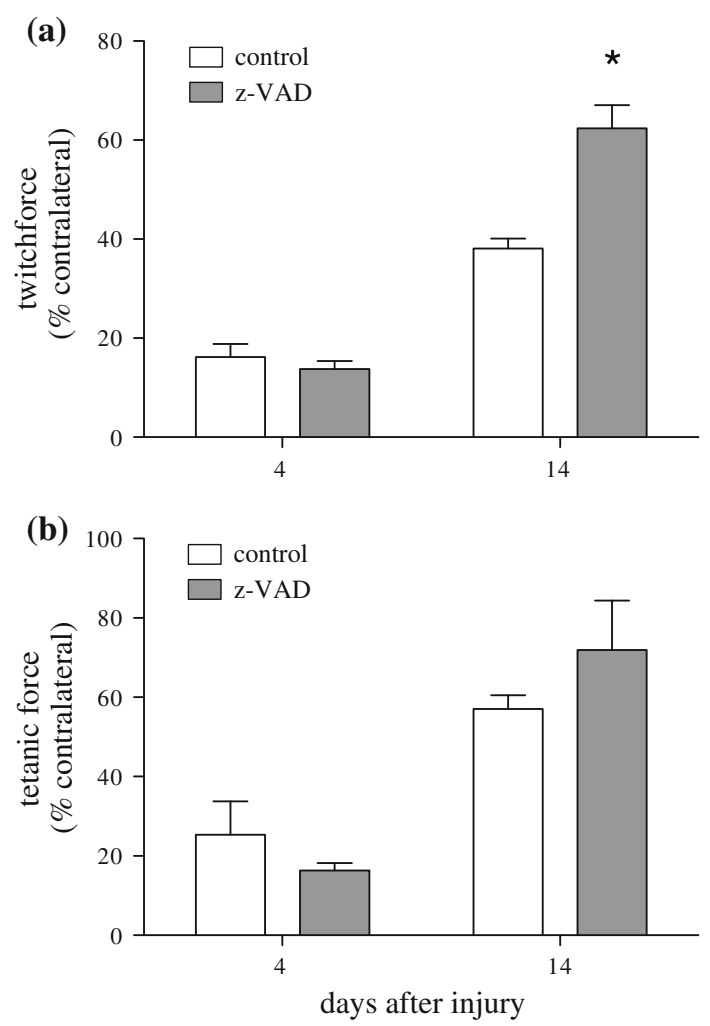

Fig. 1 Twitch (a) and tetanic (b) force in animals which underwent a standardized open crush injury to the left soleus muscle and treatment with DMSO as vehicle solution (control white bars, $n=6$ animals per time point) or pan-caspase inhibitor z-VAD.fmk (z-VAD gray bars, $n=6$ animals per time point). Analysis was performed at days 4 and 14 after injury. Data are given as means \pm SEM; $t$-test: $* P<0.05$ vs control (refer text for exact $P$ values)

fast-twitching phenotype of muscle. In contrast to DMSO treated animals maintaining the fast-twitching phenotype at day 14, animals administered z-VAD.fmk showed already a decrease in the twitch-to-tetanic force ratio, indicating an enhanced turn back to the physiological phenotype of a slow-twitching muscle [Table 1; left muscle (control vs. z-VAD): $P=0.78$ at day 4 and $P=0.05$ at day 14 ; right muscle (control vs. $\mathrm{z}-\mathrm{VAD}$ ): $P=0.18$ at day 4 and $P=0.82$ at day 14 ; control group (right muscle vs. left muscle): $P=0.03$ at day 4 and $P=0.03$ at day 14 ;
z-VAD group (right muscle vs. left muscle): $P \leq 0.001$ at day 4 and $P=0.08$ at day 14].

While muscle injury resulted in an increase of the muscle cell proliferation 4 days after injury, the incorporation of BrdU into the injured muscle tissue was significantly reduced in the z-VAD.fmk group, indicating a reduced need for proliferation (Fig. 2a and b; $P=0.04$ ). Regarding muscle cell proliferation after 14 days no significant difference could be observed between the z-VAD and the control group (Fig. $2 b ; P=0.37$ ).

Administration of z-VAD.fmk almost completely abolished cell death in the injured muscle at day 4 after injury. Accordingly, quantitative analysis of cleaved caspase 3 positive cells at day 4 after muscle injury showed a significant decrease of apoptosis in the z-VAD group compared to the control group (Fig. $3 \mathrm{a}$ and $\mathrm{b} ; P \leq 0.001$ ). At day 14 the apoptotic cell rate decreased to $2-3$ cells $/ \mathrm{mm}^{2}$ and no significant differences between both groups was observed (Fig. 3a and b; $P=0.69$ ).

Western blot analysis for the expression of the pro- and anti-apoptotic proteins bax and bcl-2 did not show any difference between the groups (Table 2; bax/ $/$-actin: $P=0.85$ at day 4 and $P=0.43$ at day 14 ; bcl-2/ß-actin: $P=0.77$ at day 4 and $P=0.86$ at day 14). Similarly the ratio of the pro- to anti-apoptotic proteins (bax/B-actin to bcl-2/ß-actin ratio) was not statistically significant between the $\mathrm{z}-\mathrm{VAD}$ and the control group (Table 2; bax/ $/$-actin per bcl-2/ß-actin: $P=0.59$ at day 4 and $P=0.89$ at day 14 ). This implies that the use of z-VAD.fmk does not involve the modulation of these proteins for its regenerative action in muscle injury.

Enhancement of muscle functions upon pan-caspase inhibition (Fig. 1a and b) was preceded by a significant increase of muscle tissue area at day 4 (Fig. $4 \mathrm{~b} ; P=0.02$ ) and slightly higher values of muscle tissue at day 14 in the $\mathrm{z}-\mathrm{VAD}$ group compared to the control group (Fig. 4b; $P=0.41)$. In addition, increased muscle cell diameter was observed at day 14 in the $\mathrm{z}-\mathrm{VAD}$ group, indicating that caspase inhibition reduced muscle cell atrophy and induced a relative muscle cell hypertrophy after muscle injury (Fig. 5b; $P=0.45$ at day 4 and $P=0.02$ at day 14).

Table 1 Twitch-to-tetanic force ratio of the right and left soleus muscle

Twitch-to-tetanic force ratio

\begin{tabular}{|c|c|c|c|c|}
\hline \multirow[b]{2}{*}{ Day } & \multicolumn{2}{|c|}{ Right (non-injured) muscle } & \multicolumn{2}{|c|}{ Left (injured) muscle } \\
\hline & Control & $z-V A D$ & Control & $\mathrm{z}-\mathrm{VAD}$ \\
\hline 4 & $0.49 \pm 0.05$ & $0.56 \pm 0.01$ & $0.70 \pm 0.08^{\#}$ & $0.73 \pm 0.05^{\#}$ \\
\hline 14 & $0.48 \pm 0.02$ & $0.49 \pm 0.03$ & $0.74 \pm 0.02^{\#}$ & $0.64 \pm 0.04 *$ \\
\hline
\end{tabular}

Animals underwent muscle injury and treatment with DMSO as vehicle solution (control) or pan-caspase inhibitor z-VAD.fmk (z-VAD). Analysis was performed at day 4 and 14 after injury. Data are given as mean \pm SEM; $n=6$ per time point and group; $t$-test: $* P<0.05$ vs control; ${ }^{\#} P<0.05$ versus right (non-injured) muscle (refer text for exact $P$ values) 
(a)
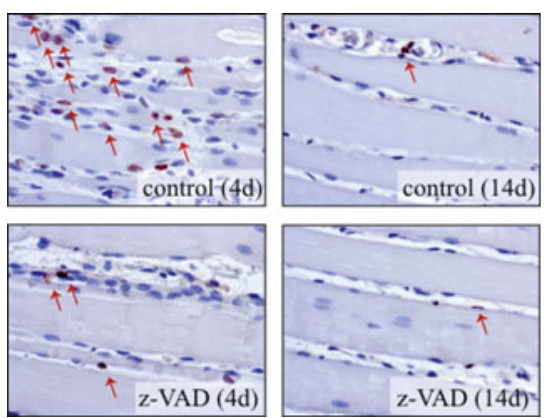

(b)
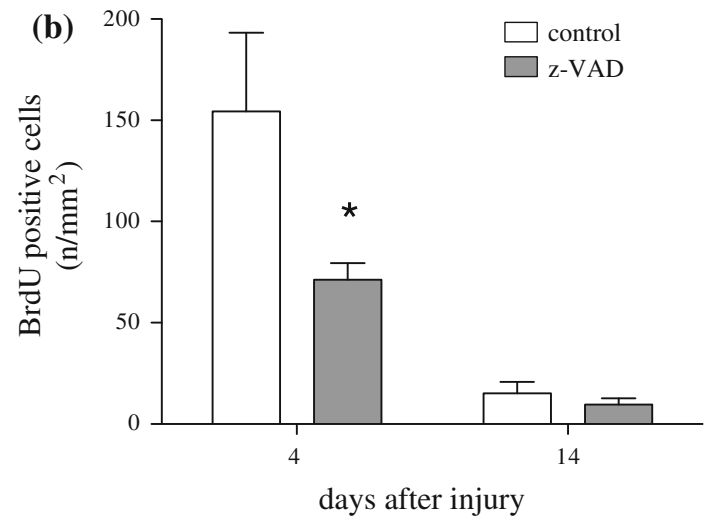

Fig. 2 Representative light microscopic images (a) of BrdU staining ( $\times 400$ magnification, arrows indicate BrdU positive cells) as well as quantitative analysis of BrdU positive cells (b). Animals underwent a standardized open crush injury to the left soleus muscle and treatment with DMSO as vehicle solution (control, white bars, $n=6$ animals per time point) or pan-caspase inhibitor z-VAD.fmk (z-VAD gray bars, $n=6$ animals per time point). Analysis was performed at days 4 and 14 after injury. Data are given as means \pm SEM; $t$-test: $* P<0.05$ versus control (refer text for exact $P$ values)

\section{Discussion}

Inhibition of caspase-mediated apoptosis supported the functional restoration of the injured muscle by amplifying the twitch and tetanic force. Furthermore z-VAD.fmk promoted the survival of the injured myofibers and decreased muscle atrophy, as indicated by the increased muscle tissue area. Thereby, the need for muscle cell proliferation at day 4 seems to be reduced. This resulted into a relative muscle cell hypertrophy at day 14 after injury and an enhanced morphological switch towards a slow-twitching phenotype of muscle.

\section{Methodological considerations}

Regarding the animal's age, it is known that younger animals experience a quicker regeneration than aged animals and old animals sustain structural and functional changes of the muscle, that lead to a reduced regenerative capacity [19]. Regarding the sex of the animals, it is postulated that female rodents experience after muscle injury less pronounced tissue (a)
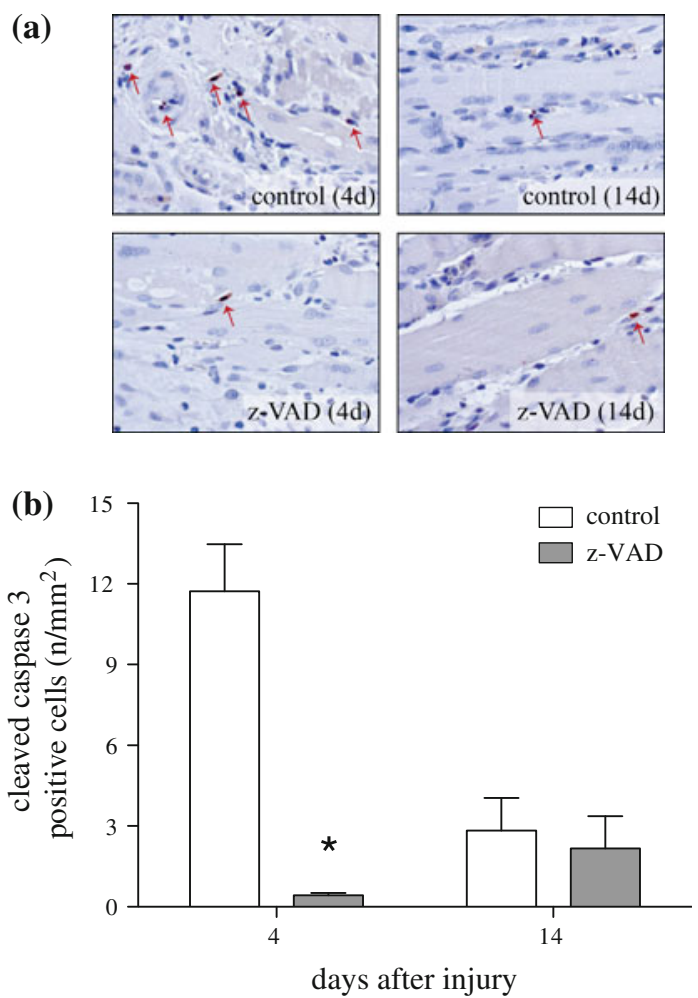

Fig. 3 Representative light microscopic images (a) of cleaved caspase 3 staining $(\times 400$ magnification, arrows indicate cleaved caspase 3 positive cells) as well as quantitative analysis of cleaved caspase 3 positive cells (b). Animals underwent a standardized open crush injury to the left soleus muscle and treatment with DMSO as vehicle solution (control white bars, $n=6$ animals per time point) or pan-caspase inhibitor z-VAD.fmk (z-VAD; gray bars, $n=6$ animals per time point). Analysis was performed at days 4 and 14 after injury. Data are given as means $\pm \mathrm{SEM}$; $t$-test: $* P<0.05$ vs control (refer text for exact $P$ values)

damage compared to equally injured males [20]. The few animal studies that have focused on gender differences after muscle injury concluded that female hormones were at least partially responsible for lower levels of muscle damage [21, 22]. Unfortunately, these experimental results in animals could not be confirmed by human studies after muscle injury, as no significant advantage in the recovery of females over males could be noted in these trials $[23,24]$. Though there is so far no evidence that the caspase could have a sex specific action in the skeletal muscle, there is evidence for gender dependent cell death pathways in the ischemic brain. In line with this, Liu et al. reported that caspase dependent cell death pathways are preferentially activated in the female brain after experimental stroke induction in mice [25] and that female but not male animals benefit from caspase inhibition.

\section{Caspase inhibition and muscle strength}

A variety of diseases and degenerative disorders like cancer, sepsis, uremia, or diabetes that are associated with loss 
Table 2 Quantitative densitometric Western blot analysis of the pro-apoptotic bax and the anti-apoptotic bcl-2 per ß-actin protein expression in soleus muscle tissue

\begin{tabular}{|c|c|c|c|c|c|c|}
\hline \multirow[b]{2}{*}{ Day } & \multicolumn{2}{|l|}{ bax/ß-actin } & \multicolumn{2}{|l|}{ bcl-2/ß-actin } & \multicolumn{2}{|c|}{ bax $/ \beta$-actin to bcl- $/ \beta$-actin ratio } \\
\hline & Control & z-VAD & Control & $\mathrm{z}-\mathrm{VAD}$ & Control & $z-V A D$ \\
\hline 4 & $0.57 \pm 0.03$ & $0.56 \pm 0.06$ & $0.47 \pm 0.06$ & $0.50 \pm 0.08$ & $1.31 \pm 0.18$ & $1.18 \pm 0.14$ \\
\hline 14 & $0.68 \pm 0.05$ & $0.74 \pm 0.05$ & $0.61 \pm 0.09$ & $0.63 \pm 0.08$ & $1.22 \pm 0.16$ & $1.25 \pm 0.15$ \\
\hline
\end{tabular}

Animals underwent muscle injury and treatment with DMSO as vehicle solution (control) or pan-caspase inhibitor z-VAD.fmk (z-VAD). Analysis was performed at day 4 and 14 after injury. Data are given as mean \pm SEM; $n=6$ per time point and group; $t$-test; no statistical significances were found

(a)
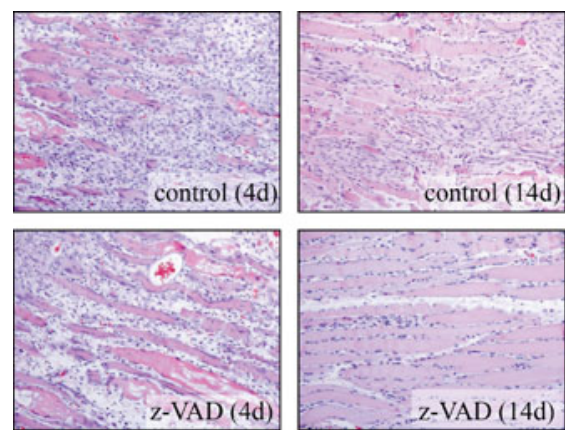

(b)

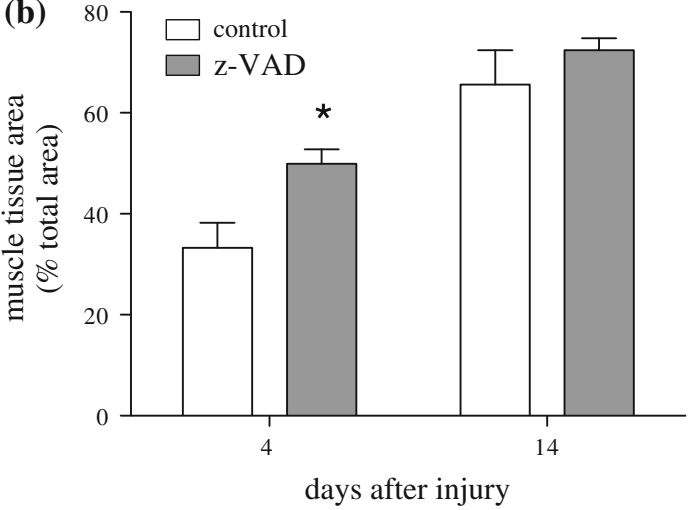

Fig. 4 Representative light microscopic images (a) of HE staining ( $\times 100$ magnification) as well as quantitative analysis of muscle tissue area (b). Animals underwent a standardized open crush injury to the left soleus muscle and treatment with DMSO as vehicle solution (control white bars, $n=6$ animals per time point) or pan-caspase inhibitor z-VAD.fmk (z-VAD gray bars, $n=6$ animals per time point). Analysis was performed at days 4 and 14 after injury. Data are given as means \pm SEM; $t$-test: $* P<0.05$ versus control (refer text for exact $P$ values)

of muscle force are accompanied by caspase activation [26]. Especially for muscle tissue the cell apoptosis is considered a key phenomenon during the pathogenesis of dystrophy, degeneration or injury. Interestingly, caspase inhibition can improve skeletal muscle force capacity in animal models of muscle disease [27-29]. In most of those conditions, caspase activation is associated with cell death, but there are few exceptions like the heart muscle where caspase activation is the consequence of cellular dysfunction [27]. Communal et al. have previously reported that (a)
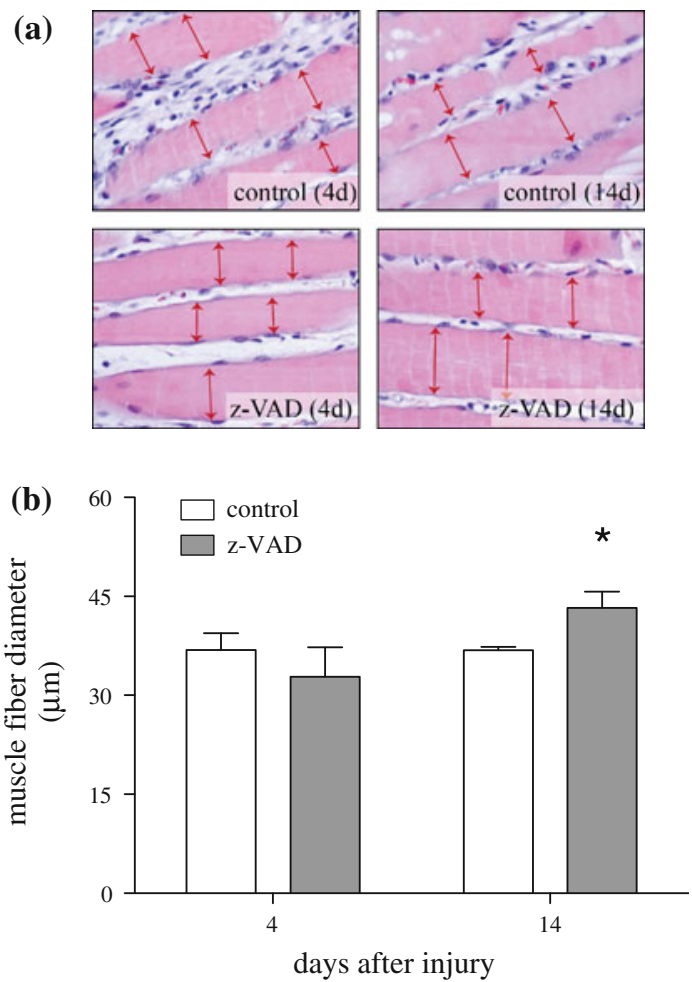

Fig. 5 Representative light microscopic images (a) of HE staining ( $\times 400$ magnification; double headed arrows indicate the myofiber diameter) as well as quantitative analysis of muscle fiber diameter (b). Animals underwent a standardized open crush injury to the left soleus muscle and treatment with DMSO as vehicle solution (control white bars, $n=6$ animals per time point) or pan-caspase inhibitor z-VAD.fmk (z-VAD gray bars, $n=6$ animals per time point). Analysis was performed at days 4 and 14 after injury. Data are given as means $\pm \mathrm{SEM}$; $t$-test: $* P<0.05$ vs control (refer text for exact $P$ values)

caspase 3 cleaved myofibrillar proteins in cardiac myocytes, disturbing the physiological link between muscle force and calcium concentration. As a consequence, inhibition of caspase 3 was followed by increased muscle strength in vitro [27]. Increased muscle strength was also observed for skeletal muscle injury during apoptosis inhibition by $\mathrm{z}$-VAD.fmk in sepsis and endotoxin-induced diaphragmatic weakness [28, 29]. Supinski and coworkers reported that the increased caspase activity in rat 
diaphragm during catabolic procedures is associated with a reduction in force generation [28]. The authors could further demonstrate that the z-VAD.fmk-associated increase of muscle strength in endotoxin-induced diaphragmatic weakness was mediated by the inhibition of the degradation of the cytoskeletal protein alpha-spectrin, which is important in maintaining cellular integrity [28]. Similar reports are published for the heart muscle, where the pancaspase inhibitor z-VAD.fmk reduced endotoxin-induced heart dysfunction and boosted the systolic performance of the left ventricle [30, 31]. In summary, current literature support our data and our primary assumption that caspase inhibition increases muscle strength and thereby augments muscle regeneration.

Skeletal muscles have a well-defined plasticity. Under certain conditions, myosin heavy chain isoforms change their protein structure, heading in the direction of either fast-to-slow or slow-to-fast twitching phenotype. Increased neuromuscular activity, mechanical loading, or hypothyroidism induces a fast-to-slow transition. On the contrary, reduced neuromuscular activity, trauma, mechanical unloading, muscular atrophy, or hyperthyroidism cause transitions into the slow-to-fast direction [32]. This morphological switch of myosin heavy chain isoforms can indirectly be verified by calculation of the twitch-to-tetanic force ratio [9]. In the current experiments muscle injury caused a transient switch towards a fast-twitching phenotype. This phenotypic switch was less pronounced 14 days after muscle injury in the $\mathrm{z}-\mathrm{VAD}$ group, probably reflecting a better and faster transformation of the injured muscle towards the normal slow-twitching phenotype.

Molecular basis of apoptosis inhibition, muscle cell hypertrophy and atrophy

Hypertrophic events after apoptosis inhibition have been described in smooth muscle cells. In support to our results, Marchand et al. described that z-VAD.fmk blocked losartan-induced smooth muscle cell death and vascular remodeling in spontaneously hypertensive rats [33]. Members of the caspase protein family do play a crucial role not only during apoptotic and degenerative events but also during muscle cell atrophy and hypertrophy. Particularly, caspases have been identified to participate in muscle atrophy during the initial step by myofibrillar proteolysis and cleavage of actomyosin [34]. As a result, Du et al. stated that inhibition of caspase activation could be a potential therapeutic target during katabolic events, trauma and disease [35]. On the contrary, continuing evidence exists that inhibition of caspase cleavage results into muscle hypertrophy. In support of that $\mathrm{Hu}$ et al. reported that transgenic mice, which selectively express the endogenous caspase inhibitor X-chromosome-linked inhibitor of apoptosis protein (XIAP) in skeletal muscles, have hypertrophic peripheral muscles compared to wildtype animals [36]. The role of anti-apoptotic processes during hypertrophy has been further highlighted by Siu et al., reporting that muscle cell hypertrophy induced by stretch overload of the patagialis muscle in birds up-regulates XIAP [37]. Caspase activity has also been associated with regenerative and proliferative processes. Moresis et al. postulated that inhibition of caspase activity improved muscle recovery, assuming firstly a non-apoptotic role for this pathway in the myogenic program and secondly that the caspase activity is necessary for the TNF-dependent inhibition of myogenesis in vivo [38]. The group could also show that the pan-caspase inhibitor $z$-VAD.fmk increased the number of regenerating myofibers after freeze injury in rats [38].

The ratio of bax and bcl-2 is indicative for mitochondrial-induced apoptosis, because bcl-2 opposes the proapoptotic activity of bax by preventing its translocation to the mitochondria [39]. Additionally, the ratio bax to bcl-2 regulate myonuclei cell survival by controlling mitochondrial membrane stability [40]. As a result disbalance between anti-apoptotic proteins and pro-apoptotic proteins induces the formation of permeable membrane pores and stimulates the mitochondrial driven apoptosis [41]. Considering the fact, that no significant difference in the bax to bcl-2 ratio was observed in the presented study it is reasonable to postulate that $\mathrm{z}$-VAD.fmk does not influence the mitochondrial driven apoptosis at least in the current injury model, but is able to enhance muscle cell regeneration predominantly via its direct action on the caspase protein family.

A variety of intracellular molecules have been identified to impede apoptosis. The inhibitors of apoptosis proteins (IAPs) are structurally and functionally related polypeptides that serve as endogenic apoptosis inhibitors. From a molecular point of view z-VAD.fmk reduces the degradation of the IAP protein family in human cells after apoptosis induction in vitro $[42,43]$. It has also been reported that a member of the IAPs family that is termed BRUCE (baculovirus IAP repeat ubiquitin-conjugating enzyme) plays a predominant role in the inhibition of the apoptosis cascade [44]. In addition, Bartke et al. described that the pan-caspase inhibitor z-VAD.fmk completely blocked BRUCE fragmentation in vitro after apoptosis induction of human cervical cancer cells [43]. Other groups have similarly analyzed the role of BRUCE during apoptosis inhibition. Jansen and coworkers have recently reported that prostaglandin $\mathrm{F} 2 \alpha$ promotes muscle cell survival and decreases muscle cell death in a BRUCE dependent way [45]. In accordance with our results Jansen et al. showed that apoptosis inhibition, induced by prostaglandin F2 $\alpha$ upregulated BRUCE expression, resulted in decreased muscle 
cell proliferation and larger myotubes [45]. All that data provide major body of evidence, that the caspase cascade influences the regeneration of injured muscle and that one of the potential pathways of actions could be the modulation of IAP expression.

\section{Future perspectives}

Current experiments identified the pan-caspase inhibitor z-VAD.fmk as a potential therapeutic target to enhance muscle regeneration following injury. Altogether our data support the concept that therapies, that modulate the programmed cell death by suppressing apoptosis, could potentially represent a promising clinical approach to cure muscle tissue after injury. Under this point of view future studies are needed to investigate how inhibitors of caspase can be safely applied to patients in order to prevent muscle dysfunction upon muscle injury and regeneration.

Acknowledgments The authors kindly thank Berit Blendow, Doris Butzlaff, Dorothea Frenz, Maren Nerowski (Institute of Experimental Surgery, University of Rostock) for excellent technical assistance.

Open Access This article is distributed under the terms of the Creative Commons Attribution Noncommercial License which permits any noncommercial use, distribution, and reproduction in any medium, provided the original author(s) and source are credited.

\section{References}

1. Herring S (1990) Rehabilitation of muscle injuries. Med Sci Sports Exerc 22(4):453-456

2. Kibler W (1990) Clinical aspects of muscle injury. Med Sci Sports Exerc 22(4):450-452

3. Jarvinen TA, Jarvinen TL, Kaariainen M, Kalimo H, Jarvinen M (2005) Muscle injuries: biology and treatment. Am J Sports Med 33(5):745-764. doi:10.1177/0363546505274714

4. Hawke TJ, Garry DJ (2001) Myogenic satellite cells: physiology to molecular biology. J Appl Physiol 91(2):534-551

5. Huard J, Li Y, Fu FH (2002) Muscle injuries and repair: current trends in research. J Bone Joint Surg Am 84-A(5):822-832

6. Marzetti E, Lees HA, Wohlgemuth SE, Leeuwenburgh C (2009) Sarcopenia of aging: underlying cellular mechanisms and protection by calorie restriction. Biofactors 35(1):28-35. doi: 10.1002/biof.5

7. Ikeda T, Kanazawa T, Otsuka S, Ichii O, Hashimoto Y, Kon Y (2009) Expression of caspase family and muscle- and apoptosisspecific genes during skeletal myogenesis in mouse embryo. J Vet Med Sci 71(9):1161-1168

8. Kerksick C, Taylor Lt, Harvey A, Willoughby D (2008) Genderrelated differences in muscle injury, oxidative stress, and apoptosis. Med Sci Sports Exerc 40(10):1772-1780. doi:10.1249/ MSS.0b013e31817d1cce

9. Stratos I, Graff J, Rotter R, Mittlmeier T, Vollmar B (2010) Open blunt crush injury of different severity determines nature and extent of local tissue regeneration and repair. J Orthop Res 28(7):950-957. doi:10.1002/jor.21063
10. Miller JB, Girgenrath M (2006) The role of apoptosis in neuromuscular diseases and prospects for anti-apoptosis therapy. Trends Mol Med 12(6):279-286. doi:10.1016/j.molmed.2006. 04.003

11. Bianchi K, Vandecasteele G, Carli C, Romagnoli A, Szabadkai G, Rizzuto R (2006) Regulation of $\mathrm{Ca}^{2+}$ signalling and $\mathrm{Ca}^{2+}$ mediated cell death by the transcriptional coactivator PGC-1 alpha. Cell Death Differ 13(4):586-596. doi:10.1038/sj.cdd. 4401784

12. Liu Y, Gampert L, Nething K, Steinacker JM (2006) Response and function of skeletal muscle heat shock protein 70 . Front Biosci 11:2802-2827

13. Adams V, Gielen S, Hambrecht R, Schuler G (2001) Apoptosis in skeletal muscle. Front Biosci 6:D1-D11

14. Primeau AJ, Adhihetty PJ, Hood DA (2002) Apoptosis in heart and skeletal muscle. Can J Appl Physiol 27(4):349-395

15. Matziolis G, Winkler T, Schaser K, Wiemann M, Krocker D, Tuischer J, Perka C, Duda G (2006) Autologous bone marrowderived cells enhance muscle strength following skeletal muscle crush injury in rats. Tissue Eng 12(2):361-367. doi:10.1089/ ten.2006.12.361

16. Stratos I, Richter N, Rotter R, Li Z, Zechner D, Mittlmeier T, Vollmar B (2011) Melatonin restores muscle regeneration and enhances muscle function after crush injury in rats. J Pineal Res. doi:10.1111/j.1600-079X.2011.00919.x

17. Rotter R, Menshykova M, Winkler T, Matziolis G, Stratos I, Schoen M, Bittorf T, Mittlmeier T, Vollmar B (2008) Erythropoietin improves functional and histological recovery of traumatized skeletal muscle tissue. J Orthop Res 26(12):1618-1626. doi:10.1002/jor.20692

18. Stratos I, Rotter R, Eipel C, Mittlmeier T, Vollmar B (2007) Granulocyte-colony stimulating factor enhances muscle proliferation and strength following skeletal muscle injury in rats. J Appl Physiol 103(5):1857-1863. doi:10.1152/japplphysiol. 00066.2007

19. Brooks SV, Faulkner JA (1994) Skeletal muscle weakness in old age: underlying mechanisms. Med Sci Sports Exerc 26(4):432-439

20. Komulainen J, Koskinen SO, Kalliokoski R, Takala TE, Vihko V (1999) Gender differences in skeletal muscle fibre damage after eccentrically biased downhill running in rats. Acta Physiol Scand 165(1):57-63

21. Moran AL, Nelson SA, Landisch RM, Warren GL, Lowe DA (2007) Estradiol replacement reverses ovariectomy-induced muscle contractile and myosin dysfunction in mature female mice. J Appl Physiol 102(4):1387-1393. doi:10.1152/ japplphysiol.01305.2006

22. Salimena MC, Lagrota-Candido J, Quirico-Santos T (2004) Gender dimorphism influences extracellular matrix expression and regeneration of muscular tissue in $\mathrm{mdx}$ dystrophic mice. Histochem Cell Biol 122(5):435-444. doi:10.1007/s00418-0040707-8

23. Clarkson PM, Hubal MJ (2001) Are women less susceptible to exercise-induced muscle damage? Curr Opin Clin Nutr Metab Care 4(6):527-531

24. Beaton LJ, Allan DA, Tarnopolsky MA, Tiidus PM, Phillips SM (2002) Contraction-induced muscle damage is unaffected by vitamin E supplementation. Med Sci Sports Exerc 34(5):798-805

25. Liu F, Li Z, Li J, Siegel C, Yuan R, McCullough LD (2009) Sex differences in caspase activation after stroke. Stroke 40(5):1842-1848. doi:10.1161/strokeaha.108.538686

26. Powers SK, Kavazis AN, DeRuisseau KC (2005) Mechanisms of disuse muscle atrophy: role of oxidative stress. Am J Physiol Regul Integr Comp Physiol 288(2):R337-R344. doi:10.1152/ ajpregu.00469.2004

27. Communal C, Sumandea M, de Tombe P, Narula J, Solaro RJ, Hajjar RJ (2002) Functional consequences of caspase activation 
in cardiac myocytes. Proc Natl Acad Sci USA 99(9):6252-6256. doi:10.1073/pnas.092022999

28. Supinski GS, Callahan LA (2006) Caspase activation contributes to endotoxin-induced diaphragm weakness. J Appl Physiol 100(6):1770-1777. doi:10.1152/japplphysiol.01288.2005

29. Supinski GS, Wang W, Callahan LA (2009) Caspase and calpain activation both contribute to sepsis-induced diaphragmatic weakness. J Appl Physiol 107(5):1389-1396. doi:10.1152/ japplphysiol.00341.2009

30. Fauvel H, Marchetti P, Chopin C, Formstecher P, Neviere R (2001) Differential effects of caspase inhibitors on endotoxininduced myocardial dysfunction and heart apoptosis. Am J Physiol Heart Circ Physiol 280(4):H1608-H1614

31. Neviere R, Fauvel H, Chopin C, Formstecher P, Marchetti P (2001) Caspase inhibition prevents cardiac dysfunction and heart apoptosis in a rat model of sepsis. Am J Respir Crit Care Med 163(1):218-225

32. Pette D, Staron RS (2001) Transitions of muscle fiber phenotypic profiles. Histochem Cell Biol 115(5):359-372

33. Marchand EL, Der Sarkissian S, Hamet P, de Blois D (2003) Caspase-dependent cell death mediates the early phase of aortic hypertrophy regression in losartan-treated spontaneously hypertensive rats. Circ Res 92(7):777-784. doi:10.1161/01.RES.000 0065619.36118 .20

34. Jackman RW, Kandarian SC (2004) The molecular basis of skeletal muscle atrophy. Am J Physiol Cell Physiol 287(4):C834C843. doi:10.1152/ajpcell.00579.2003

35. Du J, Wang X, Miereles C, Bailey JL, Debigare R, Zheng B, Price SR, Mitch WE (2004) Activation of caspase-3 is an initial step triggering accelerated muscle proteolysis in catabolic conditions. J Clin Invest 113(1):115-123. doi:10.1172/JCI18330

36. Hu J, Du J, Zhang L, Price SR, Klein JD, Wang XH (2010) XIAP reduces muscle proteolysis induced by CKD. J Am Soc Nephrol 21(7):1174-1183. doi:10.1681/ASN.2009101011
37. Siu PM, Pistilli EE, Ryan MJ, Alway SE (2005) Aging sustains the hypertrophy-associated elevation of apoptotic suppressor $\mathrm{X}$-linked inhibitor of apoptosis protein (XIAP) in skeletal muscle during unloading. J Gerontol A Biol Sci Med Sci 60(8):976-983

38. Moresi V, Pristera A, Scicchitano BM, Molinaro M, Teodori L, Sassoon D, Adamo S, Coletti D (2008) Tumor necrosis factoralpha inhibition of skeletal muscle regeneration is mediated by a caspase-dependent stem cell response. Stem Cells 26(4): 997-1008. doi:10.1634/stemcells.2007-0493

39. Cartron PF, Oliver L, Martin S, Moreau C, LeCabellec MT, Jezequel P, Meflah K, Vallette FM (2002) The expression of a new variant of the pro-apoptotic molecule Bax, Baxpsi, is correlated with an increased survival of glioblastoma multiforme patients. Hum Mol Genet 11(6):675-687

40. Dirks A, Leeuwenburgh C (2002) Apoptosis in skeletal muscle with aging. Am J Physiol Regul Integr Comp Physiol 282(2):R519-R527. doi:10.1152/ajpregu.00458.20011

41. Hengartner MO (2000) The biochemistry of apoptosis. Nature 407(6805):770-776. doi:10.1038/35037710

42. Messmer UK, Pereda-Fernandez C, Manderscheid M, Pfeilschifter J (2001) Dexamethasone inhibits TNF-alpha-induced apoptosis and IAP protein downregulation in MCF-7 cells. Br J Pharmacol 133(4):467-476. doi:10.1038/sj.bjp.0704093

43. Bartke T, Pohl C, Pyrowolakis G, Jentsch S (2004) Dual role of BRUCE as an antiapoptotic IAP and a chimeric E2/E3 ubiquitin ligase. Mol Cell 14(6):801-811. doi:10.1016/j.molcel.2004.05.018

44. Liu CH, Goldberg AL, Qiu XB (2007) New insights into the role of the ubiquitin-proteasome pathway in the regulation of apoptosis. Chang Gung Med J 30(6):469-479

45. Jansen KM, Pavlath GK (2008) Prostaglandin F2 alpha promotes muscle cell survival and growth through upregulation of the inhibitor of apoptosis protein BRUCE. Cell Death Differ 15(10):1619-1628. doi:10.1038/cdd.2008.90 